\title{
Delayed Release Capsule Dosage Form
}

National Cancer Institute

\section{Source}

National Cancer Institute. Delayed Release Capsule Dosage Form. NCI Thesaurus. Code C42902.

A capsule covered with a substance that is designed to impede the immediate release of the active and/or inert ingredient(s) after administration. 